\title{
Os diversos usos de jogos olímpicos na imprensa carioca nas décadas de 1890 a $1910^{1}$
}

Fausto AMARO ${ }^{2}$

\begin{abstract}
Resumo:
$\mathrm{Na}$ entrada do século XX, os habitantes da cidade do Rio de Janeiro vivenciavam os jogos olímpicos em múltiplos contextos. Como os jornais da época anunciavam, esses eventos podiam ser assistidos em espaços culturais variados, tais como circo, teatro e cinema. As Olimpíadas do Comitê Olímpico Internacional também eram noticiadas, porém disputavam a atenção do leitor carioca com eventos "nãooficiais", como os jogos olímpicos de Montevidéu, em 1907. O presente artigo explora a constituição de um campo olímpico na então capital do Brasil por meio da análise dos textos da mídia impressa carioca entre as décadas de 1890 e 1910.
\end{abstract}

Palavras-chave:

Jogos olímpicos. Cidade. Narrativas. Mídia.

\section{The various uses of Olympic games in the Rio de Janeiro press in the 1890 s to $1910 \mathrm{~s}$}

\begin{abstract}
:
At the beginning of the 20th century, the inhabitants of Rio de Janeiro experienced the Olympic Games in multiple contexts. As the newspapers from that time announced, those events could be attended in varied cultural spaces, such as circus, theater and cinema. The Olympics of the International Olympic Committee were also reported, but they vie for the attention of the Carioca reader with "unofficial" events, such as the Olympic games in Montevideo in 1907. The present article explores the constitution of an Olympic field in the then capital of the Brazil through the analysis of the texts of the printed media in Rio de Janeiro between the 1890s and 1910s.
\end{abstract}

Keywords:

Olympic games. City. Narratives. Media.

\section{Los diversos usos de juegos olímpicos en la prensa carioca en las décadas de 1890 a 1910}

Resumen:

En la entrada del siglo XX, los habitantes de la ciudad de Río de Janeiro experienciaban los juegos olímpicos en múltiples contextos. Como anunciaban los periódicos en aquella época, esos eventos podrían ser asistidos en variados espacios culturales, tales como circo, teatro y cine. Las Olimpiadas del Comité Olímpico Internacional también eran reportadas, sin embargo, disputaban la atención de los lectores cariocas con eventos "no oficiales", como los juegos olímpicos de 1907 en Montevideo. En este artículo se explora la creación de um campo olímpico en la entonces capital de Brasil a través del análisis de los textos de los medios impresos de Río entre las décadas de 1890 y 1910.

Palabras clave:

Juegos olímpicos. Ciudad. Narrativas. Medios de comunicación.

\footnotetext{
${ }^{1}$ Este artigo é uma versão ampliada e revisada do trabalho apresentado no GT de História da Mídia Impressa, integrante do VI Encontro Regional Sudeste de História da Mídia - Alcar Sudeste, 2016.

${ }^{2}$ Doutor em Comunicação pelo Programa de Pós-Graduação em Comunicação da Universidade do Estado do Rio de Janeiro (UERJ), com bolsa Nota 10 da Fundação Carlos Chagas Filho de Amparo à Pesqui sa do Estado do Rio de Janeiro (Faperj). Coordenador técnico do Laboratório de Comunicação, Cidade e Consumo (UERJ) e pesquisador no Laboratório de Estudos em Mídia e Esporte. E-mail: faustoarp@hotmail.com.
} 


\section{Introdução}

Qual a primeira imagem que associamos ao pensar em jogos olímpicos? ${ }^{3}$ Caso minimamente versado nos meandros do esporte, nosso imaginário pessoal recordará algum fato relacionado ao megaevento organizado pelo Comitê Olímpico Internacional (COI). O que hoje representa o ápice do calendário esportivo mundial possui seu início no século XIX. Naquele momento, um contexto histórico favorável despertava a atenção dos europeus para os feitos da Grécia helênica e consequentemente para as competições esportivas realizadas por aquela civilização. O modelo de Olimpíada que o Rio de Janeiro sediou em 2016 foi instituído por Pierre de Coubertin em 1896, com declarada inspiração nos gregos antigos. Ao contrário do discurso oficial, que impregna o senso comum, Coubertin não foi o único a propor jogos olímpicos no século XIX. Estes sequer estavam restritos às manifestações estritamente esportivas. Exibições de jogos olímpicos podiam ser presenciadas no circo ou durante as comemorações de uma data festiva.

O Rio de Janeiro, capital de uma nação que recém abolira a escravidão e instaurara a República por meio de um golpe militar, apresentava condições propícias para absorção das ideias civilizatórias associadas aos jogos olímpicos. Com uma imprensa relativamente consolidada, uma elite urbana influenciada pelo ideário europeu e um campo esportivo em franco crescimento, o Rio dispunha dos meios de divulgação, de um público em potencial e do interesse por esportes necessários à difusão do ideal olímpico. Já dizia Peter Burke sobre as transferências culturais que o "transplante só é possível em solo adequado" (2011, p. 211). Ao propor um olhar para esse processo, os textos jornalísticos selecionados para compor este artigo, oriundos de minha pesquisa doutoral, compõem um quadro mais amplo, que diz respeito ao desenvolvimento de um campo olímpico no Rio de Janeiro desde o final do século XIX até as primeiras décadas do XX.

Para acompanhar a construção dessas representações acerca dos jogos olímpicos, tenho como fontes documentais os periódicos cariocas (jornais e revistas), escolhidos

\footnotetext{
3 Para lidar com a presença de fontes que se referiam tanto aos Jogos que podemos definir como "oficiais", pois organizados pelo COI, quanto "não-oficiais", por estarem à margem ou não serem reconhecidos pela instituição máxima do esporte olímpico mundial, decidi adotar uma pequena distinção na grafia de ambos. Assim, sempre que utilizo "Jogos Olímpicos" com letras maiúsculas me refiro aos eventos "oficiais", enquanto para os "não-oficiais" adoto a grafia em minúsculas ("jogos olímpicos"), a qual também se aplica aos momentos em que trato de ambos, jogos "oficiais" e "não-oficiais".
} 
por sua relevância para a sociedade carioca de então e pela atenção dedicada aos assuntos "olímpicos". Com base nesse critério, compõe o corpus deste artigo seis jornais e uma revista: Gazeta de Notícias, O Paiz, Jornal do Brasil, Correio da Manhã, Gazeta da Tarde, O Imparcial e Revista da Semana ${ }^{4}$. A mídia impressa foi primordial na introdução e difusão do esporte e do lazer modernos na cidade do Rio de Janeiro. Enquanto atores preponderantes, esses diários conformaram certo imaginário olímpico sobre os eventos que narravam. $\mathrm{Na}$ análise das fontes, busco as singularidades que constituem a temática dos jogos olímpicos em um texto cultural bem-sucedido (cf. GEERTZ, 2008), o que, por conseguinte, suscita refletirmos sobre o espaço ocupado pelos jogos no cotidiano da sociedade carioca do período em questão. O caminho que adoto perpassa entender o processo de mediação envolvido no diálogo entre os jogos olímpicos, os media e a sociedade.

Ao esforço de reconstituir as representações sobre os jogos olímpicos, tendo por base unicamente os textos de jornais, busquei me aproximar do que Carlo Ginsburg (1989) descreve como um paradigma ou método indiciário. Trabalhar com esse método implica redobrar a atenção para as peculiaridades das fontes e, consequentemente, para as particularidades que escapam a um olhar preocupado apenas com as generalizações e enquadramentos. Quando bem utilizado, esse método permite extrair hipóteses e conclusões originais da análise de pequenos fatos, sem eliminar as incertezas inerentes à produção de narrativas sobre o passado.

O presente artigo busca, assim, apresentar um potencial campo de pesquisa histórico e midiático sobre os "primeiros momentos" dos jogos olímpicos no Rio de Janeiro (de 1890 a 1919). Isso nos conduz inexoravelmente a pensar a cidade e sua oferta de lazer e divertimentos na entrada do século XX. Com tal intuito, este texto se divide em três partes principais. Na primeira, exploro alguns aspectos da mídia impressa, baluarte da modernidade introduzida na cidade-capital. Complementarmente, abordo as ofertas de entretenimento disponíveis para o cidadão carioca. Por último, exponho resumidamente, a partir da análise de notas, crônicas e matérias jornalísticas, os múltiplos espaços ocupados pelos jogos olímpicos no Rio de Janeiro.

\section{O cenário da mídia impressa na entrada do século $\mathrm{XX}$}

\footnotetext{
${ }^{4}$ A consulta a essas fontes foi realizada no sítio on-line da Hemeroteca Digital da Biblioteca Nacional, por meio da busca por cinco termos: "jogos olympicos"/“jogos olímpicos", "olympíadas"/“olimpíadas", "olympíada"/"olimpíada", "Coubertin" e "jogos gregos".
} 
A transição Império-República, em 1889, mais do que uma mudança de formas de governo, representou uma transformação das mentalidades. Se o ideal de civilização foi o principal motor das políticas públicas durante a Monarquia, na República o progresso e o desenvolvimento material passam a pautar os melhoramentos urbanos (AZEVEDO, 2003). É nesse sentido que Pereira Passos e Rodrigues Alves ${ }^{5}$ iniciaram o processo de reforma urbana da cidade do Rio entre os anos de 1902 e 1906. Ambos buscavam dar ao Rio uma imagem cosmopolita e, ao Brasil, uma aura progressista, em oposição ao período monárquico, visto como ultrapassado e tradicional. Compreender o diálogo entre civilização e progresso na história da cidade do Rio contribui para refletirmos sobre a mídia impressa e sua cobertura dos jogos olímpicos.

O campo da imprensa era exemplar desse Rio de Janeiro que se pretendia moderno e sintonizado com as notícias e inovações oriundas do restante do mundo. Grande parte dos jornais naquele início de era republicana havia surgido ainda no final da Monarquia: Gazeta de Notícias (1875), Gazeta da Tarde (1881), O Paiz (1884), A Notícia (1884), Diário de Notícias (1885), Cidade do Rio (1887). Se a quantidade de jornais não se alterara sensivelmente a partir de 1889 (SODRÉ, N. W., 1999, p. 257), a oferta existente de opções de leitura já era, todavia, fundamental na apreensão das novidades e no estímulo ao debate na esfera pública.

Mídia hegemônica e "arauto do progresso" (RIO, 1911, p. 4), as representações veiculadas pela imprensa portavam grande apelo simbólico entre os habitantes da urbe carioca. Ao tratarmos os jornais como ícones da modernidade, é importante explorarmos justamente o que esses meios de comunicação representavam no contexto da época. A mídia reunia notícias de locais distantes no exíguo espaço de suas páginas impressas, disponibilizadas ao leitor carioca a cada manhã. Para além da dissolução de fronteiras físicas objetivas, havia a questão do tempo. As notícias ainda demoravam a chegar, mas a telegrafia, recém-instalada no Brasil, representava um significativo avanço em relação a outras formas de transmissão e recebimento de mensagens. As especificidades técnicas do meio impresso e sua materialidade eram tão prementes quanto o próprio conteúdo transmitido. A imprensa era um acontecimento em si mesma e um "ator" relevante, se preferirmos utilizar o conceito do sociólogo Bruno Latour (2012). Um serviço cada vez mais ubíquo no cotidiano da cidade.

\footnotetext{
${ }^{5} \mathrm{O}$ ordenamento e saneamento do Centro foram levados a efeito durante a prefeitura de Pereira Passos (1902-1906), parte de uma iniciativa mais ampla do governo federal (a "Regeneração"), implementada durante a presidência de Rodrigues Alves (1902-1906).
} 
A panaceia de um Rio moderno caminhava, entretanto, em descompasso com a realidade da população. Se aproximadamente metade dos 500 mil habitantes da cidade era alfabetizada em 1890 (CARVALHO, 2002, p. 22), a porcentagem de leitores devia ser ainda menor. Apesar dessa pequena população letrada, a vendagem diária dos jornais cariocas apresentava números relativamente altos já na primeira década do século $\mathrm{XX}$ (quando a população somava cerca de 800 mil habitantes). Segundo Marialva Barbosa (2007, p. 41), "as cinco mais importantes folhas da cidade - o Jornal do Brasil, o Jornal do Commercio, Gazeta de Notícias, Correio da Manhã e O Paiz” perfaziam uma tiragem total de 150 mil exemplares diários. Esses números revelam o lugar privilegiado ocupado pelos jornais no cotidiano da urbe e na vida dos cidadãos.

É plausível admitirmos também que aqueles que não possuíam as habilidades necessárias para a leitura direta dos periódicos buscariam outras formas de tornar possível a obtenção dessas informações. Como evidenciado pelo historiador Victor Melo (2001, p. 189), "era comum pagar a alguém para ler o jornal. Ou, para aqueles que não podiam pagar, solicitar que algum conhecido alfabetizado fizesse a leitura, normalmente em uma roda para várias pessoas atentas às notícias da cidade, inclusive as esportivas". Isso nos permite concluir que o fluxo de informações fornecido pela imprensa não se restringia apenas a uma pequena parcela da população capaz de consumir (ler e interpretar) tal conteúdo.

Na transição do século XIX para o XX, o Rio encontrava-se em um momento "crítico" de sua história, como o historiador Richard Morse (1993) afirmara certa vez. As mudanças no sistema político, as flutuações econômicas, as migrações para os centros urbanos, tudo isso sinalizava para novas formas de sociabilidade. As transformações em ritmo acelerado impactavam a vida cotidiana do cidadão comum. $\mathrm{O}$ trabalho, livre e assalariado desde 1888, pressupunha um tempo ocioso, que deveria ser aproveitado ao máximo. Além disso, velhos hábitos cariocas pareciam ceder, por sedução ou coerção, a novas práticas, mais modernas e próprias à República recéminstaurada. Surgia então a questão: o que fazer nesse tempo livre?

\section{O cidadão carioca e suas opções de lazer}

"Junto com a Rua do Ouvidor, sua feroz competidora na preferência do público, a Avenida Central intensificou o prazer da flânerie ou do footing, dependendo do ideal do pedestre que poderia ser influenciado pelo modelo francês ou inglês da época" 
(ARAÚJO, 1993, p. 327, grifos da autora). Essa citação estabelece uma oportuna ligação entre as mudanças urbanísticas do Rio, em curso no início do século XX, e os novos hábitos de lazer e diversão que se instauravam no mesmo período. Cariocas de todas as classes sociais passavam a ocupar com seus corpos as ruas da cidade, o que era incomum durante a vigência do regime escravocrata, quando principalmente os negros circulavam por esse espaço público, vide os escravos de ganho. Para desvelar o lugar que viria a ser ocupado pelos jogos olímpicos, devemos compreender primeiro o campo de diversões e entretenimento disponível aos cariocas.

O sociólogo Georg Simmel, em seu clássico texto A metrópole e a vida mental (1987), analisa os múltiplos estímulos sensoriais que as cidades modernas ofereciam a seus habitantes. Pode-se inferir que parte dessas estimulações fosse proveniente da crescente oferta de possibilidades de diversão. Estas surgem em um contexto onde o tempo livre passava a ser tão valorado quanto o tempo dedicado ao trabalho. Simmel fazia alusão às sociedades urbano-industriais europeias, nas quais o ritmo acelerado do trabalho fabril se coadunava com o fracionamento do tempo e a intensificação das emoções.

O cenário descrito por Simmel para a Europa pode ser aplicado, guardadas as devidas peculiaridades culturais, às mudanças vivenciadas pelo habitante da cidade do Rio de Janeiro na entrada do século XX. De sede da Corte em um regime monárquico, escravista e conservador, o Rio vivenciava a partir de 1889 o adensamento populacional, o frenesi do capitalismo reinante, o contato com ideias mais liberais e a chegada das novidades culturais europeias. Em resumo, o carioca experimentava o que seria um padrão de vida moderno, marcado, dentre outras coisas, pela utilização do espaço público para fins não utilitários stricto sensu. A conformação a esse novo modo de vida se desenvolve com vigilância do aparato estatal a fim de garantir o processo de ajustamento das camadas populares (CHALHOUB, 2012, p. 50), pois, no Rio de Janeiro, não costumava existir "uma separação muito marcada entre a hora do trabalho e a hora do lazer" (HERSCHMANN; LERNER, 1993, p. 19). É por esse motivo que o Estado passa a combater, por exemplo, os quiosques espalhados pelo Centro, onde trabalhadores, em horário "comercial", paravam para conversar e beber.

Outra prática muito combatida eram as apostas, que atingiram seu ápice de popularidade justamente na transição para o século XX. A disseminação dos jogos de azar entre todas as camadas sociais era tamanha que o fato incomodava o próprio 
prefeito, Pereira Passos, em sua busca por adequar a cidade a um padrão civilizatório europeu (BENCHIMOL, 1992, p. 278). A relação entre jogos de azar e jogos olímpicos foi cotejada pelos articulistas dos periódicos analisados, ora com argumentos favorecendo aos primeiros, ora aos segundos ${ }^{6}$.

Dentre as opções de diversão (antigas e novas) disponíveis aos cariocas, a historiadora Rosa Maria Barboza de Araújo (1993, p. 328-371) lista as seguintes: passeios familiares pelo Centro da Cidade; visitas ao Jardim Zoológico de Vila Isabel, à Quinta da Boa Vista, à Ilha do Governador, à Paquetá; festas ao ar livre; festas familiares; assistência de ritos cívicos nacionais, como o Dia da Pátria; participação em clubes, associações, bailes de caridade, festas beneficentes e reuniões dançantes; diversões na rua - praia e banhos de mar, carnaval, festas juninas, rodas de samba, cinemas e cafés; idas ao teatro e ao circo, para assistir às companhias circenses e teatrais, aos shows de variedades, ao canto lírico e às óperas.

Não menos importante nesse rol de divertimentos, o esporte já ocupava posição de relevo no cotidiano carioca desde meados do século XIX. O historiador Victor Melo (2005, p. 27-28) enumera as variedades de sport disponíveis então: touradas, brigas de galo, patinação, lutas de boxe, corridas a pé/corridas atléticas, banhos de mar, corridas de velocípedes, natação, corridas de cachorro e de pombo correio, jogo do bicho, cricket, turfe e remo. Além dessas modalidades, Araújo (1993, p. 314-317) elenca algumas outras, presentes no Rio republicano: luta romana, provas náuticas, canoagem, aviação, malha, pingue-pongue, ciclismo, automobilismo, futebol, equitação, esgrima, corrida de bicicletas. Muitos desses esportes estavam, na época, incluídos na programação das Olimpíadas do COI, enquanto outros se constituíam em hábitos locais.

É possível afirmarmos que o protagonismo do Rio de Janeiro no cenário nacional também se manifestou em sua receptividade aos novos divertimentos na virada do século XIX para o XX. Foi no Rio que pioneiramente se estruturou um campo olímpico e uma mídia impressa preocupada em lhe dar publicidade. Deve-se ressaltar, contudo, que o Rio de Janeiro não foi um receptor passivo das influências europeias.

\footnotetext{
${ }^{6}$ Um exemplo de argumento contrário aos jogos olímpicos aparece na coluna "A Semana" da Gazeta de Notícias: “[...] a população está desacostumada d'esse genero de sport, em que cada um entra com dinheiro [valor do ingresso] e sai sem elle. O uso corrente é trazerem alguns uma parte do que os outros deixam [lógica da aposta]" (A SEMANA, 29 mar. 1896, p. 1). Outras matérias, contudo, legitimavam os jogos olímpicos, em detrimento do caráter pernicioso dos jogos de azar (ver, por exemplo, O JOGO, 07 abr. 1898, p. 1).
} 
Houve um misto de aceitação, resistência e adaptação dos leitores e jornalistas cariocas aos jogos olímpicos.

\section{Os jogos olímpicos nas narrativas jornalísticas}

Pense agora nos jogos olímpicos e na cidade do Rio de Janeiro na transição do século XIX para o XX. Imagine-se como um cidadão carioca que caminha pela Avenida Central recém-inaugurada pelo governo federal. Senta-se em um banco para ler seu jornal diário e se depara, dentre o emaranhado de pequenas notas informativas, com uma notícia sobre a realização de jogos olímpicos. Qual seria sua reação? Se proveniente das camadas populares, sua ideia de diversão provavelmente não estaria tão intrinsicamente associada ao esporte (pelo menos, até a década de 1900). Jogos de azar estavam na ordem do dia e você talvez se questionasse sobre a validade de gastar seu tempo com uma diversão "estrangeira" e aparentemente sem nenhuma possibilidade de lucro. Saberia você, aliás, o que eram aqueles tais de "jogos olympicos"? Sendo membro das elites, influenciado pelos hábitos franceses e ingleses, sua opinião poderia ser outra. Em sua perspectiva, aqueles jogos, inspirados na mais alta ideia de civilização, poderiam colaborar na formação do homem nacional e no melhoramento da sociedade brasileira.

Para deslindar esse cenário, apresento abaixo algumas matérias que visam demonstrar como os jogos olímpicos estavam incluídos nas notícias jornalísticas cotidianas disponibilizadas ao carioca.

Uma série de acontecimentos "olímpicos" ocorria à margem da "oficialidade" dos eventos organizados pelo COI, dentre os quais destaco: exibições de jogos olímpicos no contexto circense ou como parte do programa de eventos comemorativos variados; temática olímpica em peças teatrais; apresentações de filmes olímpicos nos cinemas da cidade; "jogos olympicos" e "olympiadas" como palavras de uso corriqueiro com sentidos diversos; competições "não-oficiais", como as realizadas em Montevidéu (1907). Não se tratam, todavia, de forças antípodas, mas complementares, na formação de um campo olímpico na cidade do Rio. Todas essas acepções extrapolam o atual sentido hegemônico atribuído a jogos olímpicos e olimpíadas.

No primeiro caso, a prática de "jogos olympicos" era anunciada ao lado de habilidades tipicamente circenses, como malabares e equilibrismo. Várias companhias apresentavam seus números de jogos olímpicos em diferentes espaços culturais da 
cidade, dentre as quais podemos citar: "Grande Companhia Equestre e de Novidades", "Familia Jacopi" e "Companhia Silbon", no Theatro S. Pedro de Alcântara; "The 4 Fortys", no Theatro Maison Moderne; "Troupe Baltus”, no Casino; “Trio Wasnell's”, no Circo Rio de Janeiro; "The Ziras", no Pathé; "Trupe japonesa”, no Circo Spinelli. É difícil precisar do que se compunham essas exibições de jogos olímpicos, porém, a partir dos dados coletados, é possível inferir que incluíssem ginástica artística, saltos, exercícios de força, esgrima, cabo de guerra e lutas. Jogos olímpicos pareciam estar atrelados à dificuldade performática e aos exercícios físicos, prescindindo de um caráter competitivo formal (entre atletas ou equipes). A quantidade de companhias circenses anunciando seus espetáculos no Rio de Janeiro atendia ao gosto do carioca por tais atrações: os "circos eram uma forma de diversão popular e barata que atraía grande público" (MELO, 2001, p. 110). É possível inferir também que a chegada de trupes circenses internacionais, com seus números de jogos olímpicos, carregasse um simbolismo de inserção da cidade no circuito do mundo civilizado, argumento tão caro à época.

Um carioca menos entusiasta do ambiente circense, porém, curioso pelos tais jogos olímpicos, podia assisti-los em formato de películas, transmitidas nos cinemas da cidade. Na década de 1900, as telas do Cinematógrafo Parisiense exibiam imagens dos Jogos de Paris, segundo constava na coluna "Diversões" do $J B$ (GRANDE CINEMATOGRAPHO..., 28 ago. 1908, p. 16; CINEMATOGRAPHOS..., 12 out. 1908, p. 1) e na "Echos \& Factos" d'O Paiz (CINEMATOGRAPHO PARISIENSE, 28 ago. 1908, p. 1). A longevidade dessa película, que ficou quase dois meses em cartaz, e a divulgação na mídia impressa servem como indícios sobre o interesse do público pelo seu conteúdo: as cenas dos esportes olímpicos. As Olimpíadas de Estocolmo também fizeram sucesso na cidade. As filmagens dessa edição olímpica percorreram os cinemas do Rio em 1912, sendo anunciadas como o "mais bello film de sports athleticos, até hoje exibido" (AVENIDA..., 28 ago. 1912, p. 14). Desde agosto de 1912, a exibição dessas imagens era anunciada nas telas do Cinema Avenida, do Parque Fluminense e do Cinema Smart.

Na mesma época, O Paiz divulgava a peça "A Corrida de Marathon". Encenada pela companhia Nova Scena, tratava-se de "uma bella revista, de Moraitini, inspirada

\footnotetext{
${ }^{7}$ Anúncios publicados respectivamente nos jornais: Correio da Manhã (GRANDE COMPANHIA..., 18 ago. 1907, p. 8; Gazeta de Notícias (HOJE..., 13 out. 1896, p. 6; O Paiz (CONGRESSO..., 24 abr. 1890, p. 6).
} 
pelos últimos jogos olympicos" (O THEATRO..., 11 jun. 1907, p. 3). Por ocasião da inauguração de certo "Colyseu Romano", na rua do Areal n. 90, O Imparcial e o Correio da Manhã divulgavam a realização de um "festival Greco-Romano". Em benefício do "Instituto de Proteçcão e Assistência à Infância" (COLYSEU..., 16 out. 1914, p. 10), a encenação buscava "reproduzir com a maior verdade histórica os divertimentos predilectos do povo romano" (GRANDE FESTA..., 07 out. 1914, p. 2), o que incluía cenas de jogos olímpicos (NOTAVEL..., 10 out. 1914, p. 9).

Organizar eventos que incluíssem exibições de jogos olímpicos parecia ser, nesse contexto, uma alternativa eficaz para atração e divertimento do público carioca. Por conta do centenário da imprensa no Brasil, a "Associação Typographica Fluminense" pretendia promover uma série de atividades comemorativas. Dentre as ditas "diversões públicas" do evento, figuravam "jogos olympicos, floraes e sportivos, em diversos pontos da cidade e a preços modicos" (CENTENÁRIO..., 14 dez. 1907, p. 5). Saliento que, nessa época, não era incomum que as "associações de classe e as entidades políticas ou filosóficas” oferecessem "programações de lazer” (ARAÚJO, 1993, p. 3389).

A evidente atração exercida pelos divertimentos em geral e pelas exibições de jogos olímpicos em particular explica ainda a presença dessas atividades na programação de festas populares e mesmo de celebrações religiosas. Na "tradicional festa dos barraqueiros da Penha", em 1913, organizou-se um festival para a imprensa que contava com "bandas de música, fogos de artifício, jogos olympicos, corridas a pé, bailes ao ar livre, etc., etc" (FESTAS, 5 nov. 1913, p. 5). Na festa em homenagem a Nossa Senhora Auxiliadora, realizada no Colégio Salesiano (Niterói), estava prevista na programação uma parte esportiva com jogos olímpicos, compostos por: "Saltos, corridas, força e lutas" (NO COLLEGIO..., 25 maio 1919, p. 8).

Certos usos para as expressões olímpicas passavam ao largo de qualquer conotação esportiva, principalmente na década de 1890. A Gazeta da Tarde, por exemplo, publicava um texto no qual a expressão “jogos olímpicos” era utilizada em um sentido muito próximo ao de subterfúgio: “As suas dúvidas nada mais representam do que jogos olympicos para, seduzindo-nos com seu admirável encanto, mais uma vez provar-nos o seu talento e a sua proverbial sagacidade" (EMISSÃO..., 21 jan. 1890, p. 3). Outro sentido comum era o de disputa, competição, concurso, presente em expressões como: "olympiada de belleza e de elegância", "grande olympiada moderna", 
"grande olympiada do trabalho", "olympiadas de arte", "olympiadas da civilisação", "olympiada numerosa de clínicos", "jogos olympicos da grande raça britanica”, "jogos olympicos da arte", "jogos olympicos da politica", "olympiada de paz e de justiça", "olympiada de triumphos". Ao que tudo indica, tais usos podiam emprestar tanto um caráter agonístico às palavras associadas (beleza, política, arte) quanto conferir-lhes um sentido de ciclo temporal (não necessariamente de quatro anos).

Segue-se que grandes eventos esportivos que podemos denominar de "nãooficiais", pois não reconhecidos pelo COI, também estavam incluídos na seara das notícias olímpicas cariocas. Em Atenas, no ano de 1906, foi realizado um grandioso evento sob o nome de "jogos olímpicos". Em Paris, no ano de 1919, ocorreram os jogos interaliados ou olimpíadas de Pershing, reunindo os soldados das nações vitoriosas na Primeira Guerra Mundial. Ambos os eventos tiveram ampla cobertura, entretanto o episódio "olímpico" de maior vulto na imprensa carioca transcorreu na cidade de Montevidéu, em 1907. Seja por razões geográficas, que facilitavam a chegada de notícias, seja pela presença de atletas brasileiros, o acontecimento esportivo na capital uruguaia ${ }^{8}$ atraiu mais a atenção midiática do que os Jogos do COI realizados no intervalo 1896-1908. Destaco, em especial, o lugar privilegiado ocupado por Abrahão Saliture e Hermann Friese, atletas, respectivamente, do Club de Natação e Regatas (RJ) e do Sport-Club Germania (SP), que retornaram do Uruguai como verdadeiros heróis olímpicos nacionais devido às suas conquistas em provas de natação (Saliture) e nas corridas pedestres (Friese).

Dentre as questões levantadas por esse evento, destaco o amadorismo, também um dos principais valores defendidos pelo COI. Apesar de não estarem totalmente claras as exigências da organização dos jogos de Montevidéu em relação aos seus participantes, tal assunto veio à tona devido a decisão da Federação Brasileira das Sociedades do Remo por rejeitar a inscrição naquela competição de alguns atletas por ela considerados profissionais. Nesse sentido, o Jornal do Brasil (JOGOS..., 21 fev. 1907, p. 5; JOGOS..., 27 fev. 1907, p. 5) e a Gazeta de Notícias (JOGOS..., 27 fev. 1907, p. 4) publicavam as cartas de um leitor favorável à decisão da Federação e dos atletas afetados por ela, além de manifestarem suas opiniões sobre a contenda.

\footnotetext{
${ }^{8}$ Na América do Sul, além do Uruguai/1907, outros países realizaram jogos olímpicos, porém com menor repercussão nas folhas cariocas. No período aqui estudado, contabilizei doze relevantes registros de jogos olímpicos sul-americanos: Uruguai (1907 e 1919); Argentina (1909, 1910, 1912 e 1918); Paraguai (1909 e 1911); Peru (1918); Chile (1906, 1907, 1908, 1909 e 1919).
} 
Além do debate sobre o amadorismo em si, essa discussão pública lançava luz sobre alguns dos atores envolvidos no jogo da produção noticiosa. No caso, vemos em ação os diferentes públicos que atuavam no campo olímpico carioca à época: o jornal, o leitor, o atleta-leitor, a entidade esportiva, o jornalista mediador do debate. A presença desses atores no palco midiático ilustra a seguinte perspectiva de Muniz Sodré (2009, p. 41): “O enquadramento técnico do fato pelo discurso jornalístico resulta, portanto, de um amplo consenso entre atores extramidiáticos, que bem podem ser vistos como personagens de um enredo em busca de verossimilhança".

Ao longo dos anos 1890 e 1900, ocorreram também quatro edições dos Jogos Olímpicos Internacionais organizados pelo COI: Atenas/1896, Paris/1900, St. Louis/1904 e Londres/1908. A realização das Olimpíadas no eixo Europa-América do Norte, juntamente com a ausência de atletas brasileiros, que começaram a participar apenas em 1920, podem justificar a baixa incidência de notícias relacionadas a esses eventos no período estudado. As poucas informações eram veiculadas principalmente em pequenas notas de agências de notícias, e somente a partir de Londres/1908 conseguimos presenciar uma cobertura mais detalhada, enfocando inclusive a preparação da infraestrutura na cidade sede (GRANDES..., 16 abr. 1907, p. 1; UM CIRCO..., 14 abr. 1907, não paginado).

A escassez de notícias sobre os primeiros Jogos Olímpicos pode estar relacionada também ao baixo número de jornalistas cobrindo o evento in loco. Em 1896, apenas doze jornalistas estiveram presentes realizando a cobertura (SLATER, 1998, p. 51). Até onde as informações apontam, nenhum deles estava a serviço de um periódico brasileiro. Nas edições seguintes, até 1912 pelo menos, o panorama continuava o mesmo: nenhum correspondente enviado por periódicos cariocas. As notícias chegavam, assim, por meio do serviço das agências internacionais de notícias.

A despeito da pouca quantidade de informações disponível, a pesquisa sobre os Jogos Olímpicos evidenciou algumas representações difundidas pela imprensa carioca. Os textos jornalísticos tentavam aproximar o evento moderno de seu antepassado grego, o que era operacionalizado por um suposto caráter tradicional repetidamente atribuído ao primeiro ${ }^{9}$. Abordar as Olimpíadas Modernas por esse viés de continuidade linear

\footnotetext{
${ }^{9}$ Assim, por exemplo, após a abertura dos primeiros Jogos Olímpicos, em Atenas/1896, o Jornal do Brasil já afirmava tratar-se de um evento tradicional: "Athenas, 6. - Começaram aqui os tradicionnaes jogos olympicos, que despertam, como de costume, o maior interesse” (OS JOGOS..., 06-07 abr. 1896, p. 1 , grifos meus).
} 
conferia ao tema uma dose extra de atratividade, principalmente se considerarmos sua carência inicial de um repertório próprio de ritos, história e simbolismos.

Sendo um produto das nações mais proeminentes do Ocidente, as Olimpíadas apareciam relacionadas com a noção de civilização. Essa associação positiva entre os Jogos Olímpicos e os países participantes (em sua maioria, europeus ocidentais), ditos civilizados, aumentava o interesse do periodismo carioca, preocupado em inserir seu leitor nas discussões de importância global sobre o esporte e disseminar certo imaginário olímpico. A reiteração do argumento civilizacional na década de 1910 trazia em seu bojo uma implicação clara: o Brasil não pertencia ao quadro dos países civilizados, pois não participava dos Jogos. Para modificar esse cenário, a mídia impressa se engajava na busca pela inserção olímpica brasileira.

O crescimento do interesse da imprensa carioca pelos Jogos Olímpicos no início da década de 1910 era um reflexo direto dessa campanha em prol da primeira participação olímpica brasileira. Extensos textos, diversas fotografias, cartas, telegramas e regulamentos publicados na íntegra, tudo isso fora incorporado às páginas de esporte dos jornais cariocas. O leitor experimentava uma nova relação com a notícia, pois tinha à sua disposição conteúdos mais completos e descobria, por meio das imagens, os rostos dos personagens do esporte olímpico nacional e internacional. Nessa mesma época, observam-se algumas tentativas de organização de jogos olímpicos locais, competições que reuniriam os esportes olímpicos já difundidos no Rio de Janeiro, servindo ao propósito de promover a cultura olímpica para o restante do país e preparar os atletas brasileiros para os Jogos Olímpicos Internacionais. O próprio Comitê Olímpico Nacional, fundado em oito de junho de $1914^{10}$, tem como embrião o comitê olímpico provisório criado para organizar os jogos olímpicos brasileiros no ano de 1913 (uma iniciativa do Jornal do Brasil).

Depois dos Jogos de Estocolmo/1912, o Congresso Olímpico de junho de 1914 foi o fato mais amplamente divulgado pela imprensa carioca, juntamente com a carta enviada por Raul do Rio Branco ${ }^{11}$ no mês anterior. Nesse congresso, o COI autorizava o Brasil a participar da próxima edição dos Jogos Olímpicos, que até então seria realizada em Berlim/1916. O ingresso brasileiro nesse organismo representava metaforicamente o bilhete de entrada para o mundo ocidental, moderno e capitalista. Na imprensa carioca,

\footnotetext{
${ }^{10}$ A Gazeta de Notícias afirmava no dia seguinte que o "Comité Olympico Brasileiro é um facto" (A CREAÇÃO..., 09 jun. 1914, p. 4).

${ }^{11}$ Ministro brasileiro na Suíça e primeiro delegado do COI para o Brasil.
} 
o clima para 1916 era de entusiasmo diante da perspectiva de participação brasileira. Figuras como Raul do Rio Branco, Almeida Brito, Arnaldo Guinle, Fernando Mendes de Almeida, Alvaro Zamith, Duarte Rodrigues, Conde de Penha Garcia, Ulysses Reymar surgem na década de 1910 como protagonistas da vida esportiva carioca e nacional. Lado a lado com esses indivíduos e as instituições que eles representavam, as corporações jornalísticas desempenhavam papel de relevo na organização e propaganda de um campo olímpico em formação.

Detalhar os inúmeros movimentos do esporte olímpico nacional na década de 1910 me faria exceder os limites deste artigo, por isso gostaria de enfatizar apenas mais alguns pontos. O primeiro está relacionado ao evidente aumento do interesse da mídia carioca pelos Jogos Olímpicos ao longo da década de 1910, derivados do maior envolvimento brasileiro com o movimento olímpico internacional. Em igual medida, crescia o descontentamento com a inércia do poder público em relação ao esporte e à cultura física. A ausência brasileira em Jogos Olímpicos mexia com os brios patrióticos e influenciava negativamente a construção de uma identidade nacional, dois motes do jornalismo esportivo naquele momento. Ao largo dessas constatações, o diálogo entre os periódicos e os leitores passava a se estabelecer em novas bases. Isto é, a produção de um conteúdo pedagógico sobre a história dos Jogos modernos e antigos já tornava possível, em alguns momentos, que o jornal tratasse o leitor não mais como um neófito no tema. É assim, por exemplo, que o Jornal do Brasil atestava: “Já os leitores estão cansados de saber que a próxima Olympiada Internacional (VI) se realizará em Berlim, em 1916" (A OLYMPIADA..., 28 abr. 1913, p. 18).

Desse modo, uma cultura olímpica começava a se espraiar pela cidade nas três décadas aqui enfocadas. Não expus um fio condutor único para as narrativas apresentadas, justamente porque seus sentidos não são unívocos, mas variados. Os jogos olímpicos não estavam situados somente no campo esportivo, mas também no campo do lazer, do entretenimento, das novas práticas corpóreas, das modificações urbanísticas em curso. Os jornais aqui estudados fornecem indícios que nos permitem reconstruir os espaços ocupados pelos jogos olímpicos.

\section{Considerações finais}

Os jogos olímpicos como vistos nas décadas de 1890 a 1910 eram capazes de circular por diferentes espaços culturais disponíveis à época. Os exemplos levantados ao 
longo deste artigo dão margem para que situemos os jogos como algo para além do esporte. A diversidade de usos das expressões "jogos olympicos" e "olympiadas" no corpus analisado sugere a penetração social do tema e, ao mesmo tempo, a ausência de uma preocupação explícita do Comitê Olímpico Internacional em regular o uso de suas principais marcas. Tal preocupação começa a surgir timidamente apenas na década de 1910.

Os argumentos da imprensa carioca em prol do olimpismo circulavam em torno dos benefícios corporais, do melhoramento da "raça" nacional, da preparação para a guerra, da formação do caráter; todos eles, elementos que confluiriam para a formação de uma sociedade moderna. "Educar o corpo e disciplinar hábitos significava integrar o país no perfil do mundo moderno e civilizado" (ARAÚJO, 1993, p. 312). Estava posta então a hipótese de que os jogos olímpicos atuariam como agentes modernizantes e instrumentos de ajustamento das classes trabalhadoras a uma nova ordem social e econômica (capitalista). De acordo com Sidney Chalhoub (2012), o Rio de Janeiro, na entrada do século XX, experimentava um processo de inserção ao capitalismo internacional, o qual tornava necessário o auxílio do aparato jurídico-policial para reprimir os resquícios de tradição no cotidiano carioca.

Assim, o cenário que se configura nas três primeiras décadas analisadas nos mostra como os jogos olímpicos conquistaram seu espaço nos periódicos cariocas e por quais vias as narrativas desses meios influenciaram a formação da opinião do público leitor. De uma exótica atração da virada do século até a panaceia olímpica da década de 1910, momento no qual os jogos olímpicos passam a ser vistos como uma possível solução para os problemas brasileiros, tivemos muitos episódios emblemáticos. A importância da mídia carioca para a difusão do campo olímpico justifica pensá-la, como tenho feito até aqui, não apenas como fonte histórica profícua, mas como um ator que contribuiu para tornar a história olímpica brasileira possível. Os próprios periódicos reivindicavam para si esse lugar de promotores do esporte, e não de meros espectadores ou repórteres dos fatos.

\section{Referências}

A CREAÇÃO do Comité Olympico Brasileiro e da Federação Brasileira de Sports. Gazeta de Notícias, Rio de Janeiro, p. 4, 09 jun. 1914.

A OLYMPIADA de Berlim em 1916. Jornal do Brasil, Rio de Janeiro, p. 18, 28 abr. 1913. 
A SEMANA. Gazeta de Notícias, Rio de Janeiro, p. 1, 29 mar. 1896.

AVENIDA: jogos olympicos em Stockholm. Correio da Manhã, Rio de Janeiro, p. 14, 28 ago. 1912.

ARAÚJO, Rosa Maria Barboza de. A vocação do prazer. A cidade e a família no Rio de Janeiro republicano. Rio de Janeiro: Rocco, 1993.

AZEVEDO, André Nunes. Da Monarquia à República: um estudo dos conceitos de civilização e progresso na cidade do Rio de Janeiro entre 1868 e 1906. 2003. 327 f. Tese (Doutorado em História) - Programa de Pós-graduação em História Social da Cultura, PUC-RJ, Rio de Janeiro, 2003.

BARBOSA, Marialva. História cultural da imprensa: Brasil, 1900-2000. Rio de Janeiro: Mauad X, 2007.

BENCHIMOL, Jaime Larry. Pereira Passos: um Haussmann tropical: a renovação urbana da cidade do Rio de Janeiro no início do século XX. Rio de Janeiro: Secretaria Municipal de Cultura, Turismo e Esportes, Departamento Geral de Documentação e Informação Cultural, Divisão de Editoração, 1992.

BURKE, Peter. Variedades de história cultural. Rio de Janeiro: Civilização Brasileira, 2011.

CARVALHO, José Murilo de. Cidadania no Brasil. O longo caminho. Rio de Janeiro:

Civilização Brasileira, 2002.

CENTENÁRIO da imprensa no Brasil. Jornal do Brasil, Rio de Janeiro, p. 5, 14 dez. 1907.

CHALHOUB, Sidney. Trabalho, lar e botequim: o cotidiano dos trabalhadores no Rio de Janeiro da belle époque. Campinas, SP: Editora da Unicamp, 2012.

CINEMATOGRAPHO parisiense. O Paiz, Rio de Janeiro, p. 1, 28 ago. 1908.

CINEMATOGRAPHOS: Paris. Jornal do Brasil, Rio de Janeiro, p. 1, 12 out. 1908.

COLYSEU romano. Jornal do Brasil, Rio de Janeiro, p. 10, 16 out. 1914.

CONGRESSO de maravilhas: Companhia Silbon. O Paiz, Rio de Janeiro, p. 6, 24 abr. 1890.

EMISSÃO e crédito. Gazeta da Tarde, Rio de Janeiro, p. 3, 21 jan. 1890.

FESTAS. O Paiz, Rio de Janeiro, p. 5, 5 nov. 1913.

GEERTZ, Clifford. A Interpretação das culturas. Rio de Janeiro: LTC, 2008.

GINSBURG, Carlo. Mitos, emblemas, sinais: morfologia e história. São Paulo: 
Companhia das Letras, 1989.

GRANDE cinematographo parisiense. Jornal do Brasil, Rio de Janeiro, p. 16, 28 ago. 1908.

GRANDE companhia equestre e de novidades. Correio da Manhã, Rio de Janeiro, p. 8, 18 ago. 1907.

GRANDE festa greco-romana. Correio da Manhã, Rio de Janeiro, p. 2, 07 out. 1914.

GRANDES e pequenos acontecimentos. Correio da Manhã, Rio de Janeiro, p. 1, 16 abr. 1907.

HERSCHMANN, Micael; LERNER, Kátia. Lance de sorte: o futebol e o jogo do bicho na Belle Époque carioca. Rio de Janeiro: Diadorim, 1993.

HOJE - uma soirée abulhier. Gazeta de Notícias, Rio de Janeiro, p. 6, 13 out. 1896.

JOGOS olympicos. Jornal do Brasil, Rio de Janeiro, p. 5, 21 fev. 1907.

JOGOS olympicos. Jornal do Brasil, Rio de Janeiro, p. 5, 27 fev. 1907.

JOGOS olympicos. Representação fluminense. Gazeta de Notícias, Rio de Janeiro, p. 4, 27 fev. 1907.

LATOUR, Bruno. Reagregando o social. Salvador: Edufba; Bauru, SP: Edusc, 2012.

MELO, Victor Andrade de. Cidade esportiva: primórdios do esporte no Rio de Janeiro. Rio de Janeiro: Relume Dumará; Faperj, 2001.

Lazer, esporte e cultura urbana: conexão Rio de Janeiro Paris: meio de transporte: arte. In: CONGRESSO DO CENTRO DE MEMÓRIA DA EDUCAÇÃO FÍSICA, 2., 2005, Belo Horizonte. Disponível em: <http://www.lazer.eefd.ufrj.br/producoes/esporte_lazer_urbano_ceme_ufmg_2005.pdf>. Acesso em: 14 maio 2016.

MORSE, Richard. Prefácio. In: ARAÚJO, Rosa Maria Barboza. A vocação do prazer. A cidade e a família no Rio de Janeiro republicano. Rio de Janeiro: Rocco, 1993, p. 1523.

NO COLlEGIO de Santa Rosa. Correio da Manhã, Rio de Janeiro, p. 8, 25 maio 1919.

NOTAVEL festival greco-romano. O Imparcial, Rio de Janeiro, p. 9, 10 out. 1914.

O JOGO. Gazeta de Notícias, Rio de Janeiro, p. 1, 07 abr. 1898.

OS JOGOS olympicos. Jornal do Brasil, Rio de Janeiro, p. 1, 06-07 abr. 1896.

O THEATRO na Grecia. O Paiz, Rio de Janeiro, p. 3, 11 jun. 1907. 
RIO, João do. Vidas vertiginosas. Rio de Janeiro: H. Garnier Livreiro-Editor, 1911.

SIMMEL, Georg. A metrópole e a vida mental. In: VELHO, Otávio G. (Org.). O fenômeno urbano. Rio de Janeiro: Guanabara, 1987, p. 11-25.

SLATER, Joan. Changing partners: the relationship between the mass media and the olympic games. In: Fourth International Symposium for Olympic Research. London, Ontario, 1998.

Disponível em: <http://library.la84.org/SportsLibrary/ISOR/ISOR1998h.pdf>. Acesso em: 30 abr. 2016.

SODRÉ, Muniz. A narração do fato: notas para uma teoria do acontecimento. Petrópolis: Vozes, 2009.

SODRÉ, Nelson Werneck. História da imprensa no Brasil. Rio de Janeiro: Mauad, 1999.

UM CIRCO monstro. Revista da Semana. Rio de Janeiro, não paginado, 14 abr. 1907.

Submetido em: 12.08.2016

Aprovado em: 02.07.2018 